\title{
Contribution of Protease, Lipase, Hemolysin and Biofilm in Persist of Staphylococcus aureus Isolated from Food Sources
}

\section{Khlood Abid-Alelah Alkhafaji*, Iman Sabaa Khames, Mohamed Mosa Jaffer, Safaa Abid Alrahem Mahmood and Mohammed Abid Alraheem Abidalah}

Department of Applied Microbiology, Center of Food and Biotechnology, Agricultural Research Department, Ministry of Science and Technology, Iraq

*Corresponding Author: Khlood Abid - Alelah Alkhafaji, Department of Applied Microbiology, Center of Food and Biotechnology, Agricultural Research Department, Ministry of Science and Technology, Iraq.

Received: July 30, 2019; Published: September 16, 2019

DOI: $10.31080 /$ ASAG.2019.03.0649

\section{Abstract}

The main objectives of this research are: detect the contamination of some local food product by Staphylococcus aureus and their ability to excrete protease, lipase, hemolysin enzyme and formation of biofilm, all in three temperatures (35,20 and 8) Centigrade. Thirty samples from each of Meat containing product, yogurts, cheese were randomly chosen from local markets in Baghdad city during February and March 2018. Also hospitalist samples were included in this study. Each sample was diluted to $10 \%$ peptone water, incubated at $37^{\circ} \mathrm{C}$ for 2 hour then streaked on Mannitol salt agar and bed- Barker tullerite agar to isolate S. aureus. Sixty out isolate of $S$. aureus were isolated from samples, biofilm as well as, protease, lipase and hemolysin were secreted at $35^{\circ} \mathrm{C}$ after 48 hour while seven day was needed for production at $20^{\circ} \mathrm{C}$ comparing with negligible growth or enzymatic activity at $8^{\circ} \mathrm{C}$ even after three weeks of incubation. Results showed that 25 isolates of $S$. aureus was from meat containing food products, while ten out of $S$. epidermidis was from yogurt, two from cheeses and five isolate from hospitalist samples. Environmental isolates were susceptible to penicillin $\mathrm{G}$, tetracycline, chloramphenicol and naledix acid while tetracycline, chloramphenicol and naledix acid resistance were appeared in hospitalist isolates.

Keywords: Food Product; Staphylococcus aureus; Biofilm Formation

\section{Introduction}

Low hygiene practices in food processing and manufacturing plant may lead to the contamination of foods and their products with different type of microorganisms that cause either food deterioration or a serious health risk for consumers. Moreover, the most challenge in food industry is the complete elimination of such microorganisms from food processing environments because bacteria can attach to food surfaces or the equipment in plant and form biofilm, where they survive and withstand for long time even after cleaning and disinfection [1,2]. The most harmful contaminant for humans and economic animals is the Staphylococcus. Species of Staphylococci are ubiquitous in the environment and can be found in the air, dust, sewage, water, environmental surfaces as well as mammals and birds [3].

The bacterial genus Staphylococcus has many members with high health risk for humans and many other animals. The most virulence species is $S$. aureus that require high viable number $10^{5}$ $10^{6} \mathrm{cfu} \mathrm{gm}^{-1}$ of food to produce many toxins and enzymes which play a critical role in virulence and bacterial maintenance in their environment niches. It contaminates many food, food products, milk and diary products. The transfer of $S$. aureus to food and their products through two main sources: human carriage during food processing, infected animals and contaminated equipment in the factory. This contamination depends on many factors including food quality, processing methods, temperature and duration of storage, season and general sanitation in manufacture area [2-4]. Thus in the last decades, staphylococci and their toxins had also emerged as important and potential pathogen for human and animal $[3,5]$. The success of $S$. aureus as a pathogen and its ability to cause such a wide range of infections are the result of its extensive virulence factors such as extracellular enzymes and biofilm formation beside toxins $[6,7]$.

lipases produced from $S$. aureus could increase the rate of food deterioration through their action on lipids causing accumulation of intermediate and end products that change the flavor of foods $[8,9]$. Also, staphylococcal lipase has relevance on the pathogenicity of S. aureus it degrades other substrate like plasma and fats that accumulate on the surface of the body.

Alpha hemolysin play a critical role in staphylococcal ability to cause infection through leucocidal activity that permit a rapid multiplication of bacteria and allowing for production of a large amount of other toxin [10]. On the other hand, S. aureus excrete three types of proteases; serine, cysteine and metalloprotease 
which may responsible for their virulence and persistence in environment [11-13].

Another virulence factors is the capability of bacterial community to adhere to biotic or abiotic surfaces to form biofilm that aid many advantages to bacteria. Such advantages include higher resistance to harsh environmental conditions, resist to antimicrobial agents and enhance protection from the immune system. Since biofilms are known to be a source of bacterial persistence many approaches will help to combat biofilm formation $[14,15]$.

The aims of this research were screening of protease, lipases and hemolysin activity at 8,20 and $37^{\circ} \mathrm{C}$ from $S$. aureus that isolated from different foods as well as hospitalized isolates. Biofilm formation from isolates was screened to predict their ability to cause epidemic prevalence.

\section{Material and Methods}

Samples collection and isolation of Staphylococcus spp

Thirty samples from each of Meat containing product, yogurts, cheeses and spices were randomly chosen from local markets in Baghdad city during February and March 2018. Also hospitalist samples were included in this study. Each sample was diluted to $10 \%$ peptone water, incubated at $37^{\circ} \mathrm{C}$ for 2 hour then streaked on Mannitol salt agar to isolate $S$. aureus and S. epedermidis and on Baird - Packer tullerite agar to identify coagulase positive $S$. aureus.

\section{Screening of extracellular enzymes}

The production of Lipase, protease and hemolysin were all screened at different temperature that includes 8,20 and $35^{\circ} \mathrm{C}$ for at least 7 day period of incubation.

Rhodamine B and Tween 80 method were analyzed to screen Lipase enzyme activity. Breifly, Rhodamine B method was achieved for screening of true lipases according to Kouker and Erich [16]. Briefly, nutrient agar was supplemented with $2.5 \%$ olive oil, $3 \%$ of Arabic gum and sterilized, $1 \%$ solution of $1 \mathrm{mg} \mathrm{ml}-1$ Rhodamine B stain was added, mixed and poured in petri dishes. Lipase producing isolates gave florescence orange color.

Also tween 80 method was used for screening of both lipases and esterases. The appearance of a halo zone around growth of S. aureus isolates on the top of $1 \%$ tween 80 agar was indicated for esterases activity while development of obscure region around growth indicated for lipases activity [17].

\section{Baird}

Packer agar augmented with potassium tellurite and egg yolk was chosen for the detection of Phospholipases (licithinase). Opaque region around growth was indicated for licithinase enzyme. Also, nutrient agar supplemented with $1 \%$ egg yolk was used and clear zone indicated for licithinase enzyme [18].

Skim milk agar was prepared for the detection of protease enzyme; $5 \%$ skimmed milk was dissolved in sterilized distilled water, mixed with sterilized solution of agar and poured in petri dishes.
The appearance of clear zone around bacterial culture indicated as a positive result.

Alpha, beta and gamma hemolysis of blood was screened on $7 \%$ blood agar.

\section{Detection of biofilm and slime formation}

Two different methods were used in detection of biofilm formation, tube method and congo red method which described by Christensen., et al. [19] Bose., et al. [20], Gundogan., et al. [21]. Brain heart infusion medium containing $1 \%$ sucrose was divided into 5 $\mathrm{ml}$ portion in glass vials, sterilized, cooled and inoculated by test bacteria, incubated statically at 8,20 and $37^{\circ} \mathrm{C}$ for $72 \mathrm{~h}$. growths were withdrawn, glass vials were air dried. Biofilm formation recorded as +++ (heavily positive), ++ (moderate positive), + (weak positive) and - for negative biofilm formation.

The second method was based on Congo red stain $0.8 \%$ that incorporated into brain heart infusion agar containing $1 \%$ sucrose. Bacterial isolates were streaked and incubated at different temperature for $72 \mathrm{~h}$, black colonies with a dry crystalline consistency indicated for biofilm formation; while, bright red to black colonies were established as slime formation.

\section{Antibiotic susceptibility test}

Antibiotic susceptibility test was done by agar diffusion method using standard antibiotic discs [22]. Discs of Penicillin G (30), tetracycline (10), endoxan (10) and chloramphenicol (10) were applied at experiment. Development of clear zone around bacterial growth was an indicative for bacterial susceptibility while growth around disc indicated for bacterial resistance.

\section{Results and Discussions}

At present work Many Staphylococcus spp contaminated different food grade and food products; S. aureus differentiated from meat containing medium and cheese samples. These isolates developed on Baird - Packer tellurite medium and Mannitol salt agar while S. epidrmidis isolated from yogurt and cheese samples figure 1. Spices containing each S. aureus, S. epidermidis and Bacillus spp. While, hospitalized samples contained $S$. aureus (17 isolates) and S. epidermidis ( 5 isolates) and table 1 outline the type of samples and Staphylococcus isolates.

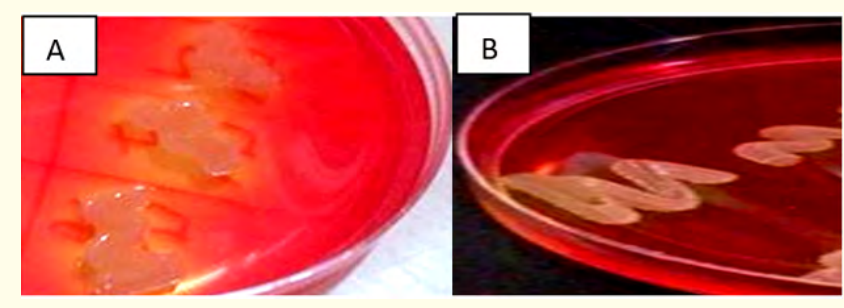

Figure 1: Identification of Staphyloccoccus spp on Mannitol salt agar

$A=$ mannitol ferment isolates; $B=$ non mannitol ferment isolates. 


\begin{tabular}{|l|c|c|c|c|c|}
\hline \multicolumn{1}{|c|}{ Sample type } & No of isolates & MSA & BPT agar & Coagulase test & Characterization \\
\hline Meat containing food & 25 & Yellow color & Black color with pricipitate & + & Staphylococcus aureus \\
\hline spices & 7 & Yellow & Black precipitate & + & Staphyloccocus aureus \\
& & Pink & No- precipitate & - & Staphylococcus epidermidis \\
& & & & & Bacillus \\
\hline yogurt & 20 & yellow & No- precipitate & - & Staphylococcus epidermidis \\
& 7 & Yellow & Black precipitate & + & Staphyloccocus aureus \\
& & Pink & No- precipitate & - & Staphylococcus epidermidis \\
& & & & & \\
\hline Hospitalized & 22 & Yellow & Black precipitate & + & Staphylococcus epidermidis \\
& & Pink & No- precipitate & & - \\
\end{tabular}

Table 1: Isolation and characterization of Staphylococcus spp from different samples.

Food borne bacteria are the most dangerous among bacterial community and many bacterial species are produce one or more of toxins that results of food poisoning. Coagulase positive strains of $S$. aureus and other related Staphyloccoccus spp are the most common food related pathogenic bacteria [23]. Different foods and their products may become contaminated during or after processing in plant field or at markets; workers as Tamp (2001) and Gundogan [21] referred to isolate $S$. aureus strains from meat and meat products, chicken, milk and dairy products.

Different environment consider as a natural niches for $S$. aureus to survive and multiplication; foods and their products provide a convenient and enrich source for their growth and subsequently causing outbreaks. Foods that involved in outbreaks differ from country to another due to food habits [24]. On the other hand, many factors may influence the growth, multiplication and production of virulence factors of $S$. aureus on foods such as the nutritional value of food, temperature, $\mathrm{pH}$ and competition with other microflora of food. Such assumption is agree with present results that $S$. aureus didn't contaminate yogurt product which might due to the presence of Lactobacillus spp that reduce $\mathrm{pH}$ value as well as the production of extracellular inhibitor substances as $\mathrm{H}_{2} \mathrm{O}_{2}$, volatile compounds, nutritional competitions and antibiotics [25]. In addition, the most effective way for inactivation of $S$. aureus in milk is heat treatment that caused complete destruction of bacterial cell.

Results showed that twenty five isolates of $S$. aureus came from meat containing products; they excrete different hydrolytic enzymes at different temperatures as presented in table 2 . All isolates produced alpha hemolysin at $37^{\circ} \mathrm{C}$ and $20^{\circ} \mathrm{C}$ while little growth appeared at blood agar without hemolysis of blood when incubated at $8^{\circ} \mathrm{C}$. Lipase enzyme produced at $8^{\circ} \mathrm{C}$ after prolonged incubation that reached to 7 days. While, protease excretes from $72 \%$ of isolates at 37 and $20^{\circ} \mathrm{C}$ with slightly growth at $8^{\circ} \mathrm{C}$ without detectable protease enzyme activity. The excretion of extracellular hydrolytic enzymes influenced with temperature, time period, food grade and strain isolate as discussed by Hennekinne [3] and outlined that at low temperature around $7^{\circ} \mathrm{C}$ there are excretion of toxin after 3 - 4 days of incubation.

Despite that the action of hemolysin, protease and lipase enzyme can change the quality of food rich with lipid, fat, fatty acid and proteins resulting in decreased the shelf life of foods and their product, $S$. aureus hydrolytic enzymes collectively can act to damage the immune system and skin barrier causing several infections $[26,27]$.

Many reports deal with the extracellular hydrolytic enzymes (Hemolysin, protease, phospholipase and lipase) production by $S$. aureus and $S$. epidermidis due to their importance in persistence and pathogenicity [12,21]. Beside hemolytic activity of Alpha hemolysin, it may related with cytotoxic, dermonecrotic and lethal activity to cell line and the toxin of interest in cow associated mastitis (Halpin - Dohnalek and Marth 1989).

The consequence of lipase production from $S$. aureus that isolated from food results from their importance in lipid metabolism as well as their role in pathogenicity of this bacterium (Cadielux 2014).

The isolates with high protease activity may be cause many infections in human and animals and such suggestion is in accordance with Gundogan., et al. [21] who reported that protease from $S$. aureus caused dermatitis in chickens.

Screening of $S$. aureus from milk containing products showed that yogurt samples (11 samples) contaminated with either Bacillus spp (4 isolates) or S. epidermidis (16 isolates). All S. epidermidis isolates produced alpha hemolysin; whereas, only one isolate produced protease and lipase at 37 and $20^{\circ} \mathrm{C}$. Cheese samples (4 samples) contaminated with $S$. aureus and $S$. epidermidis; five distinct isolate characterized as $S$. aureus and two other as $S$. epidermidis and table 3 summarized their enzymatic activity at corresponding temperature. 


\begin{tabular}{|c|c|c|c|c|c|c|c|c|c|}
\hline Isolate no & Hemolysin & & & Iipase & & & Protease & & \\
\hline & $37 \mathrm{C}$ & $20 \mathrm{C}$ & $8 \mathrm{C}$ & 37C & $20 \mathrm{C}$ & $8 C$ & $37 \mathrm{C}$ & $20 \mathrm{C}$ & $8 C$ \\
\hline 1 & +++ & +++ & - & - & - & + & - & - & - \\
\hline 2 & +++ & +++ & - & - & - & + & - & - & - \\
\hline 3 & +++ & ++ & - & - & - & + & +++ & ++ & + \\
\hline 4 & ++++ & ++ & - & - & - & + & ++++ & ++ & + \\
\hline 5 & +++ & +++ & - & - & - & + & - & - & - \\
\hline 6 & +++ & +++ & - & - & - & + & - & - & - \\
\hline 7 & +++ & +++ & - & - & - & + & - & - & - \\
\hline 8 & +++ & +++ & - & - & - & + & - & - & - \\
\hline 9 & ++ & + & - & - & - & + & ++ & + & - \\
\hline 10 & ++ & + & - & - & - & + & ++ & + & - \\
\hline 11 & ++ & + & - & - & - & + & ++ & + & - \\
\hline 12 & ++ & + & - & - & - & + & ++ & + & - \\
\hline 13 & ++ & + & - & - & - & + & ++ & + & - \\
\hline 14 & ++ & + & - & - & - & + & ++ & + & - \\
\hline 15 & ++ & + & - & - & - & + & ++ & + & - \\
\hline 16 & ++ & + & - & - & - & + & ++ & + & - \\
\hline 17 & ++ & + & - & - & - & + & ++ & + & - \\
\hline 18 & ++ & ++ & - & - & - & + & ++ & ++ & - \\
\hline 19 & +++ & ++ & - & - & - & + & +++ & ++ & + \\
\hline 20 & +++ & ++ & - & - & - & + & +++ & ++ & + \\
\hline 21 & ++ & + & - & - & - & + & ++ & + & - \\
\hline 22 & +++ & ++ & - & - & - & + & +++ & ++ & + \\
\hline 23 & ++ & ++ & - & - & - & + & ++ & ++ & + \\
\hline 24 & + & + & - & - & - & + & + & + & - \\
\hline 25 & + & + & - & - & - & + & + & + & - \\
\hline
\end{tabular}

Table 2: The production of hydrolytic enzymes from Staphylococcus aureus isolated from meat products Lipase + at $8^{\circ} \mathrm{C}$ after 7 days of incubation.

\begin{tabular}{|c|c|c|c|c|c|c|c|c|c|}
\hline \multicolumn{10}{|c|}{ Staphylococcus aureus } \\
\hline \multirow[t]{2}{*}{ Isolate No } & \multicolumn{3}{|c|}{ Hemolysin } & \multicolumn{3}{|c|}{ lipase } & \multicolumn{3}{|c|}{ Protease } \\
\hline & $37^{\circ} \mathrm{C}$ & $20^{\circ} \mathrm{C}$ & $8^{\circ} \mathrm{C}$ & $37{ }^{\circ} \mathrm{C}$ & $20^{\circ} \mathrm{C}$ & $8 \circ \mathrm{C}$ & $37^{\circ} \mathrm{C}$ & $20^{\circ} \mathrm{C}$ & $8 \cdot \mathrm{C}$ \\
\hline 1 & +++ & - & - & - & - & - & ++ & + & - \\
\hline 2 & +++ & + & - & - & - & - & ++ & + & - \\
\hline 3 & +++ & + & - & +++ & - & - & +++ & ++ & + \\
\hline 4 & ++++ & - & - & +++ & +++ & - & ++++ & ++ & + \\
\hline 5 & +++ & + & - & +++ & ++ & - & ++ & + & - \\
\hline \multicolumn{10}{|c|}{ Staphylococcus epidermidis } \\
\hline 6 & +++ & - & - & - & - & - & ++ & - & - \\
\hline 7 & +++ & + & - & - & - & - & ++ & - & - \\
\hline
\end{tabular}

Table 3: The production of hydrolytic enzymes from Staphylococcus spp isolated from cheese.

Screening of hydrolytic enzymes from hospitalized isolates indicated that hemolysin enzyme, lipase and protease were all predominant from characterized S. aureus and S. epidermidis; lipase enzyme recognized by both methods Rhodamine B and tween 80 method (Figure 2). Hemolysin, lipase enzyme produced by $31 \%$ of isolates at $37^{\circ} \mathrm{C}$ and decreased to $18.18 \%$ at $20^{\circ} \mathrm{C}$ in comparison with protease enzyme which produced by $100 \%$ of isolates at $37^{\circ} \mathrm{C}$ and lessen to $31 \%$ at $20^{\circ} \mathrm{C}$ as summarized in table 4 .

The results of Biofilm formation for the 25 isolates of $S$. aureus from meat products indicated that $100 \%$ of isolates produced biofilm at $37_{0} \mathrm{C}$ (Figure 2) while, the percentage decreased to $65 \%$ at 


\begin{tabular}{|c|c|c|c|c|c|c|c|c|c|}
\hline \multicolumn{10}{|c|}{ Staphylococcus aureus } \\
\hline \multirow[t]{2}{*}{ Isolate No } & \multicolumn{3}{|c|}{ Hemolysin } & \multicolumn{3}{|c|}{ lipase } & \multicolumn{3}{|c|}{ Protease } \\
\hline & $37^{\circ} \mathrm{C}$ & $20^{\circ} \mathrm{C}$ & $8^{\circ} \mathrm{C}$ & $37^{\circ} \mathrm{C}$ & $20^{\circ} \mathrm{C}$ & $8^{\circ} \mathrm{C}$ & $37^{\circ} \mathrm{C}$ & $20^{\circ} \mathrm{C}$ & $8^{\circ} \mathrm{C}$ \\
\hline 2 & +++ & - & - & +++ & - & - & ++ & + & - \\
\hline 8 & ++++ & - & - & + & - & - & ++ & + & - \\
\hline 9 & +++ & - & - & + & - & - & +++ & ++ & + \\
\hline 13 & +++ & + & - & ++ & +++ & - & ++++ & ++ & + \\
\hline \multicolumn{10}{|c|}{ Staphylococcus epidermidis } \\
\hline 20 & +++ & + & - & ++++ & ++ & - & ++ & + & - \\
\hline 21 & +++ & + & - & ++ & + & - & ++ & + & - \\
\hline 22 & +++ & + & - & ++ & + & - & ++ & + & - \\
\hline
\end{tabular}

Table 4: The production of hydrolytic enzyme from hospitalist isolates of Staphylococcus spp.

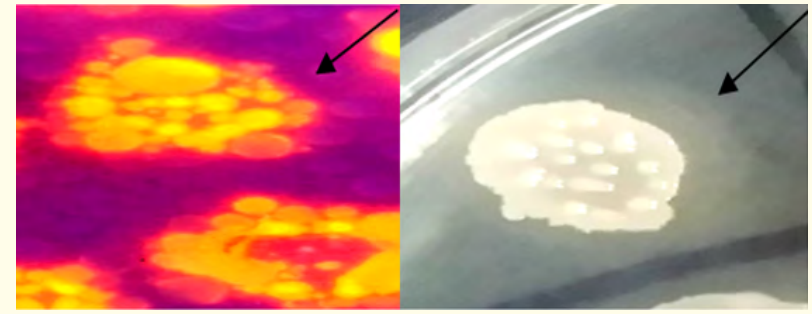

Figure 2: Screening of lipase enzyme from hospitalized isolate of Staphylococcus aureus

Left= Rhodamine B method; right= tween 80 method.

$20^{\circ} \mathrm{C}$ and to less than $10 \%$ at $8^{\circ} \mathrm{C}$ because of the low growth of bacterial biomass.

There were observed ability to form slime layer at $37^{\circ} \mathrm{C}$ from Staphylococcus spp isolates from cheese. While, at $20^{\circ} \mathrm{C}$ only S. aureus could form slime layer and none of isolates produced the slime layer at $8^{\circ} \mathrm{C}$.

Results obtained for hospitalized isolates revealed that S. aureus and S. epidermidis isolates could formed only slime layer at $37^{\circ} \mathrm{C}$.

Also, all isolates formed slime layer with the appearance of slimy bacterial growth with red color (Figure 3).
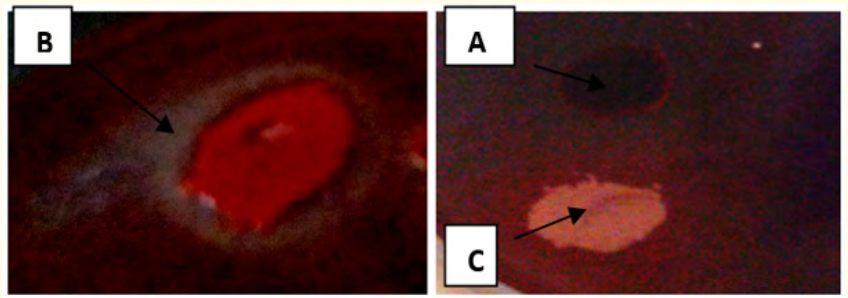

Figure 3: Formation of biofilm and slime layer on congo red medium by Staphylococcus spp isolate.

$\mathrm{A}=$ biofilm formation, $\mathrm{B}=$ slime layer formation, $\mathrm{C}=$ no- biofilm.
The phenomenon of biofilm formation is due to the aggregation of bacteria either on biotic or abiotic material and embedded in extracellular matrix composed mainly of polysaccharides and to some extent proteins and DNA [28]. The formation of these highly organized multicellular complexes is accomplished as a major and important virulence factor in S. aureus [29,30]. On the other hand, biofilm can lead to persistent contamination or infection due to resist sanitation procedures applied at plants and to the action of the host immune system of human and animals beside the resistance to antibiotics. [15]. The surfaces that come in contact with different foods and their products are very important vehicles for $S$. aureus multiplication and transmission of this bacterium and while, S. aureus can adhere to many food contact surface, they developed biofilm and affects on the quality and safety of foods [31]. Many factors that influence the formation of biofilms in S. aureus that include genotype of bacterial community, temperatures, period time, the composition of medium, static or dynamic conditions for testing biofilm, procedures that applied in biofilm formation $[32,33]$.

Our results for biofilm formation from $100 \%$ of $S$. aureus isolates of meat containing products and formation of slime layer from isolates belong to cheese and yogurt is in accordance with other work of Souza [2] and Avila - Novoa (2018) who found that $S$. aureus from meat and dairy industries formed biofilm which resist sanitation, cleaning and chemical removal for biofilm, the explanation of such finding is that meat enriched medium and milk containing products facilitate the formation of biofilm.

The ability of hospitalized S. aureus and S. epidermidis to form slim layer at $37^{\circ} \mathrm{C}$ is an indication for their importance at medicinal level. This suggestion is assimilate to [34] who noticed that many non- coagulate species of Staphylococcus other than S. aureus may be responsible for nosocomial infections and many are involved in animal diseases $[35,36]$.

\section{Conclusion}

Recent results of antibiotic susceptibility showed that $S$. aureus isolated from meat containing food products, yogurt and cheese samples were susceptible to penicillin G, tetracycline, chloramphenicol and endoxan while they resist nalidexic acid. The isolates 
of $S$. epidermids isolated from cheese resisted penicillin G, chloramphenicol and nalidexic acid which supports the idea of being responsible for public health concern.

\section{Bibliography}

1. Tamarapu S., et al. "Development of a multiplex Polymerase chain reaction assay for detection and differentation of Staphylococcus aureus in dairy products". Journal of Food Protection 64.5 (2001): 664-668.

2. De Souza EL., et al. "Biofilm formation by Staphylococcus aureus from food contact surfaces in a meat-based broth and sensitivity to sanitizers". Brazilian Journal of Microbiology 45.1 (2014): 67-75.

3. Hennekinne J- A., et al. "Staphylococcus aureus and its food poisoning toxins: characterization and outbreak investigation". FEMS Microbiology Reviews 36.4 (2012): 815-836.

4. Bremer PJ., et al. "Laboratory scale clean-inplace (CIP) studies on the effectiveness of different caustic and acid wash steps on the removal of dairy biofilms". International Journal of Food Microbiology 106.3 (2006): 254-262.

5. Quinn PJ., et al. "Staphylococcus species: Clinical Veterinary Microbiology". Section 2. Bacteriology, 8. Mosby-YearBook Europe Limited, Lynton House, London, England (1994):118126.

6. Karmakar A., et al. "Biochemical and Molecular Analysis of Staphylococcus aureus Clinical Isolates from Hospitalized Patients". Canadian Journal of Infectious Diseases and Medical Microbiology, (2016): 1-7.

7. Reddy PN., et al. "An Update on Clinical Burden, Diagnostic Tools, and Therapeutic Options of Staphylococcus aureus". Infectious Diseases: Research and Treatment 10 (2017): 1-15.

8. Takeuchi S., et al. "Purification and characterization of protease produced by Staphylococcus aureus isolated from adiseased chicken". Veterinary Microbiology 67.3 (1999): 195-202.

9. Jaeger KE., et al. "Bacterial biocatalysts: molecular biology, three dimensional structures, and biotechnological applications of lipases". Annual Review of Microbiology 53 (1999): 315-351.

10. Vandenesch F., et al. "Staphylococcus aureus Hemolysins, bicomponent Leukocidins, and Cytolytic Peptides: A Redundant Arsenal of Membrane-Damaging Virulence Factors?". Frontiers in Cellular and Infection Microbiology 2 (2012): 12.

11. Sorensen SB., et al. "Fragmentation of proteins by S. aureus strain V8 protease. Ammonium bicarbonate strongly inhibits the enzyme but does not improve the selectivity for glutamic acid". FEBS Letters 294.3 (1991):195-197.
12. Kolar SL., et al. "Extracellular proteases are key mediators of Staphylococcus aureus virulence via the global modulation of virulence-determinant stability". Microbiology 2.1 (2013): 1834.

13. Akram M., et al. "Characterization of a Thermostable Alkaline Protease from Staphylococcus aureus S-2 Isolated from Chicken Waste". Pakistan Journal of Zoology 46.4 (2014): 11251132.

14. Gutiérrez D., et al. "Incidence of Staphylococcus aureus and Analysis of Associated Bacterial Communities on Food Industry Surfaces". Applied and Environmental Microbiology 78.24 (2012): 8547-8554.

15. Song M., et al. "Biofilm formation and antibiotic resistance pattern of dominant Staphylococcus aureus clonal lineages in China". Journal of Food Safety 37.2 (2016): e12304.

16. Kouker G and Jaeger K-E. "Specific and Sensitive Plate Assay for Bacterial Lipases". Applied and Environmental Microbiology 53.1 (1987): 211-213.

17. Slifkin M. “Tween 80 opacity test responses of various Candida species". Journal of Clinical Microbiology 38.12 (2000): 46264728.

18. Otoole DK. "Differences in egg yolk reaction on Baird- Packer medium between bovine and human strains of coagulase positive staphylococci”. Letters in Applied Microbiology 4 (1987): 111-112.

19. Christensen GD., et al. "Adherence of slime-producing strains of Staphylococcus epidermidis to smooth surfaces". Infection and Immunity 37.1 (1982): 318-326.

20. Bose S., et al. "Detection of Biofilm Production Staphylococci: Need of The Hour". Journal of Clinical and Diagnostic Research 3 (2009): 1915- 1920.

21. Gundogan N and Ataol O. "Biofilm, protease and lipase properties and antibiotic resistance profiles of staphylococci isolated from various foods". African Journal of Microbiology 7.28 (2013): 3582-3588.

22. Bauer AW., et al. "Antibiotic susceptibility testing by a standardized single disk method". The American Journal of Pathology 45.4 (1966): 493-496.

23. Jablonski LM and Bohach GA. "Staphylococcus aureus. Food Microbiology Fundamentals and Frontiers (Doyle MP, Beuchat LR and Montville TJ, eds)". American Society for Microbiology Press (1997): 353-357.

24. Le Loir Y., et al. "Staphylococcus aureus and food poisoning". Genetics and Molecular Research 2.1 (2003): 63-76. 
25. Fornitano ALP., et al. "Lactobacillus rhamnosus versus Staphylococcus aureus: influence on growth and expression of virulence factors". Journal of Dental and Maxillofacial Research 2.2 (2019): 29-33.

26. Shaw L., et al. "The role and regulation of the extracellular proteases of Staphylococcus aureus". Microbiology 150 (2004):217-228.

27. Reddy PN., et al. "Evaluation of IgY capture ELISA for sensitive detection of alpha hemolysin of Staphylococcus aureus without staphylococcal protein A interference". Journal of Immunological Methods 391.1-2 (2013): 31-38.

28. Gowrishankar S. et al. "Coral associated bacteria as a promising antibiofilm agent against methicillin resistant and susceptible Staphylococcus aureus biofilms". Evidence-Based Complementary and Alternative Medicine (2012): 862374.

29. Tang J., et al. "Effects of different cultivation conditions on Staphylococcus aureus biofilm formation and diversity of adhesion genes". Journal of Food Safety 32 (2013):210-218.

30. Lee SHI., et al. "In vitro biofilm formation by Staphylococcus aureus isolated from wounds of hospital-admitted patients and their association with antimicrobial resistance". International Journal of General Medicine 11 (2018): 25-32.

31. Srey S., et al. "Biofilm formation in food industries: a food safety concern”. Food Control 31.2 (2013): 572-585.

32. Thiran E., et al. "Biofilm formation of Staphylococcus aureus dairy isolates representing different genotypes". Journal of Dairy Science 101.2 (2018):1000-1012.

33. Oulahal N., et al. "Quantitative analysis of survival of Staphylococcus aureus or Listeria innocua on two types of surfaces: Polypropylene and stainless steel in contact with three different dairy products". Food Control 19.2 (2008): 78-185.

34. Raad I., et al. "Staphylococcus epidermidis: Emerging resistance and need for alternative agents". Clinical Infectious Diseases 26.5 (1989): 1182-1187.

35. Cruz AG and Oliveira CAF. "Biofilm-producing ability of Staphylococcus aureus isolates from Brazilian dairy farms". Journal of Dairy Science 97.3 (2014): 1812-1816.

36. Washington DC. "Studies on the effectiveness of different caustic and acid wash steps on the removal of dairy biofilms". International Journal of Food Microbiology 106: 254-262.

\section{Volume 3 Issue 10 October 2019 \\ (c) All rights are reserved by Khlood Abid-Alelah \\ Alkhafaji., et al.}

